\title{
Erratum: Ferosekhan et al. Influence of Genetic Selection for Growth and Broodstock Diet n-3 LC-PUFA Levels on Reproductive Performance of Gilthead Seabream, Sparus Aurata. Animals 2021, 11, 519
}

\author{
Shajahan Ferosekhan 1,2,*(D), Serhat Turkmen 1,3 (D), Cathaysa Pérez-García ${ }^{1}$, Hanlin Xu ${ }^{1}$ D, Ana Gómez ${ }^{4}$, \\ Nazeemashahul Shamna ${ }^{5}$, Juan Manuel Afonso ${ }^{1}$, Grethe Rosenlund ${ }^{6}$, Ramón Fontanillas ${ }^{6}$, Anselmo Gracia ${ }^{1}$, \\ Marisol Izquierdo ${ }^{1}$ and Sadasivam Kaushik ${ }^{1}$ (D)
}

check for updates

Citation: Ferosekhan, S.; Turkmen S.; Pérez-García, C.; Xu, H.; Gómez,

A.; Shamna, N.; Afonso, J.M.; Rosenlund, G.; Fontanillas, R.; Gracia, A.; et al. Erratum: Ferosekhan et al. Influence of Genetic Selection for Growth and Broodstock Diet n-3 LC-PUFA Levels on Reproductive Performance of Gilthead Seabream, Sparus Aurata. Animals 2021, 11, 519. Animals 2021, 11, 2957. https:// doi.org/10.3390/ani11102957

Received: 16 August 2021 Accepted: 9 October 2021 Published: 14 October 2021

Publisher's Note: MDPI stays neutral with regard to jurisdictional claims in published maps and institutional affiliations.

Copyright: (c) 2021 by the authors. Licensee MDPI, Basel, Switzerland. This article is an open access article distributed under the terms and conditions of the Creative Commons Attribution (CC BY) license (https:/ / creativecommons.org/licenses/by/ $4.0 /)$.
1 IU-ECOAQUA, Universidad de Las Palmas de Gran Canaria, Taliarte, 35214 Telde, Spain; turkmen@uab.edu (S.T.); cathaysa.perez108@alu.ulpgc.es (C.P.-G.); hanlinxuulpgc@outlook.com (H.X.); juanmanuel.afonso@ulpgc.es (J.M.A.); anselmo.gracia@ulpgc.es (A.G.); marisol.izquierdo@ulpgc.es (M.I.); sachi.kaushik@ulpgc.es (S.K.)

2 ICAR-Central Institute of Freshwater Aquaculture, Bhubaneswar 751002, Odisha, India

3 Department of Biology, University of Alabama at Birmingham, Birmingham, AL 35294, USA

4 Institute of Aquaculture Torre de la Sal (IATS), CSIC, Ribera de Cabanes, 12595 Castellón, Spain; a.gomez@csic.es

5 ICAR-Central Institute of Fisheries Education, Mumbai 400061, Maharashtra, India; shamna@cife.edu.in

6 Skretting Aquaculture Research Centre, Sjohagen, 4016 Stavanger, Norway; Grethe.Rosenlund@skretting.com (G.R.); ramonfontanillas@gmail.com (R.F.)

* Correspondence: feroseaqua@gmail.com

The authors wish to make the following corrections to this paper [1].

1. Delete "Acknowledgments".

2. Change in Funding.

Funding: This study was funded by the EU-funded project AQUAIMPACT (Genomic and Nutritional Innovations for Genetically Superior Farmed Fish), grant agreement No. 818367, PROGENSA III (Mejora de la competitividad del sector de la dorada a través de la selección genética, JACUMAR program with support from the European Maritime and Fisheries), and the Indian Council of Agricultural Research (ICAR), New Delhi, India.

\section{Reference}

1. Ferosekhan, S.; Turkmen, S.; Pérez-García, C.; Xu, H.; Gómez, A.; Shamna, N.; Afonso, J.M.; Rosenlund, G.; Fontanillas, R.; Gracia, A.; et al. Influence of Genetic Selection for Growth and Broodstock Diet n-3 LC-PUFA Levels on Reproductive Performance of Gilthead Seabream, Sparus aurata. Animals 2021, 11, 519. [CrossRef] [PubMed] 